\title{
Mecanismos de aclimatação das plantas à elevada concentração de $\mathrm{CO}_{2}$
}

\author{
Acclimation mechanisms to elevated $\mathrm{CO}_{2}$ in plants
}

Lidiane Cristine Walter $^{I^{*}}$ Hamilton Telles Rosa ${ }^{\mathrm{I}}$ Nereu Augusto Streck ${ }^{\mathrm{II}}$

RESUMO

O metabolismo vegetal sofre alterações com o aumento da concentração de $\mathrm{CO}_{2}$ na atmosfera terrestre. Inicialmente, a taxa fotossintética aumenta pela maior disponibilidade de $\mathrm{CO}_{2}$, após determinado tempo de exposição, observa-se algumas adaptações a fim de retornar ao equilibrio inicial, caracterizando a aclimatação. $O$ objetivo desta revisão foi descrever os mecanismos responsáveis pela aclimatação das plantas à elevada concentração de $\mathrm{CO}_{2}$ na atmosfera. Num curto prazo, enzimas e outras substâncias importantes para a fotossintese começam a ficar escassas pelo metabolismo acelerado. Além disso, o amido excedente da elevada taxa fotossintética acumula-se no interior de cloroplastos, podendo prejudicar a fotossintese. Num periodo mais longo de exposição, observa-se um decréscimo da vantagem produtiva do ambiente com elevado $\mathrm{CO}_{2} e$ uma distribuição da biomassa, que favorece as partes vegetativas. A aclimatação no longo prazo está relacionada com a capacidade de o vegetal aumentar seus compartimentos de armazenamento.

Palavras-chave: fotossíntese, mudança climática, adaptação.

\section{ABSTRACT}

The plant metabolism is altered with increasing of $\mathrm{CO}_{2}$ concentration in the atmosphere. Initially the photosynthetic rate increases by the greater $\mathrm{CO}_{2}$ available, after some time there is some adaptations in order to return to the initial equilibrium, characterizing acclimation. The objective of this review was to describe the acclimation mechanisms in plants to elevated $\mathrm{CO}_{2}$ concentration. In the short term, enzymes and other important substances for photosynthesis are scarce by accelerated metabolism. In addition, excess starch of high photosynthetic rate, accumulated within chloroplasts can impair photosynthesis. A longer period there is a decrease in productive advantage on high $\mathrm{CO}_{2}$ environment and biomass distribution that favors vegetative parts. Acclimation in the long term is related to the plant ability to increase its storage compartments.

Key words: photosynthesis, climate change, adaptation

\section{INTRODUÇÃO}

Por ser um substrato primário para que $\mathrm{o}$ processo de fotossíntese ocorra, a quantidade de $\mathrm{CO}_{2}$ disponível para as plantas tem efeito direto na taxa fotossintética, que tende a ser maior quando a concentração desse gás na atmosfera também é maior (TAIZ \& ZEIGER, 2013). O aumento da concentração de $\mathrm{CO}_{2}$ desde a revolução industrial e as projeções futuras deste componente atmosférico estabelecem um cenário favorável ao aumento da fotossíntese, e, consequentemente, da produtividade primária em comunidades vegetais, com potencial impacto positivo sobre o desempenho dos agroecossistemas. Segundo TAIZ \& ZEIGER (2013), a taxa fotossintética da maioria das espécies vegetais pode ter um aumento de 30 a $60 \%$ em ambiente com concentrações de 600 a 700ppm de $\mathrm{CO}_{2}$ atmosférico, em relação à taxa de fotossíntese com 370 ppm de $\mathrm{CO}_{2}$ na atmosfera.

Apesar do aumento da taxa fotossintética em elevadas concentrações de $\mathrm{CO}_{2}$, observa-se que este efeito não é constante ao longo do ciclo das culturas e muitas vezes não resulta em aumento de produtividade (ARENQUE et al., 1014; KIM et al., 2011; CALIMAN et al., 2009; YANG et al., 2006), por ser afetado pelo processo da aclimatação. A aclimatação das plantas à elevada concentração de $\mathrm{CO}_{2}$ atmosférico consiste em uma série de alterações no metabolismo vegetal em diferentes níveis de organização (desde molecular e bioquímico até anatômico e morfológico). Considerando a escala

Instituto Federal de Educação, Ciência e Tecnologia Farroupilha (IF Farroupilha), Campus Santo Augusto, Rua Fábio João Andolhe, n. 1100, Bairro Floresta, CP 33, 98590-000, Santo Augusto, RS, Brasil. E-mail: lidianewalter@gmail.com. *Autor para correspondência.

IDepartamento de Fitotecnia, Centro de Ciências Rurais (CCR), Universidade Federal de Santa Maria (UFSM), Santa Maria, RS, Brasil. 
de tempo para que aconteça a aclimatação, algumas alterações podem se desenvolver após um curto prazo de exposição (minutos/horas) caracterizando a aclimatação no curto prazo; enquanto outras ocorrem após um longo período (dias/semanas), caracterizando a aclimatação no longo prazo (CALIMAN, 2008).

A aclimatação dos vegetais, avaliada pela taxa fotossintética, leva a uma preocupação a respeito de sua consequência na resposta do crescimento e produtividade das culturas agrícolas ao aumento da concentração de $\mathrm{CO}_{2}$ atmosférico, projetada até o final do século XXI. Esta revisão bibliográfica teve como objetivo descrever os mecanismos responsáveis pela aclimatação das plantas à elevada concentração de $\mathrm{CO}_{2}$ na atmosfera, no curto prazo e no longo prazo.

Aumento da concentração de $\mathrm{CO}_{2}$ na atmosfera

A concentração de dióxido de carbono $\left(\mathrm{CO}_{2}\right)$ na atmosfera terrestre, cerca de 397,6ppm em janeiro de 2014 (NOAA, 2014), pode sofrer alterações em decorrência de forçantes naturais ou pela interferência da atividade humana (IPCC, 2013). De acordo com o quinto relatório do Painel Intergovernamental de Mudança Climática (IPCC, 2013), a ação antrópica tem contribuído para um aumento significativo na concentração de $\mathrm{CO}_{2}$ na atmosfera terrestre, entre outros gases de efeito estufa. Esse aumento iniciou a partir da revolução industrial, quando o crescimento das grandes cidades e indústrias fez aumentar a queima de combustíveis fósseis (carvão mineral, petróleo e gás natural), lançando uma grande quantidade de $\mathrm{CO}_{2}$ e outros poluentes na atmosfera.

A reconstrução e caracterização da atmosfera em climas passados pode ser feita através de análises de indicadores, como anéis de árvores e testemunhos de gelo (MANN et al., 1999), ou pela estimativa com modelos de regressão (von STORCH et al., 2004). Segundo estimativas citadas no IPCC (2007), os valores pré-industriais da concentração de $\mathrm{CO}_{2}$ seriam de $280 \mathrm{ppm}$ em 1750 , oscilando entre 180 e 300 ppm durante 650.000 anos, sendo historicamente muito abaixo dos valores observados atualmente. Com base nessas indicações de aumento recente na concentração de $\mathrm{CO}_{2}$ na atmosfera terrestre, e considerando que a queima de combustíveis fósseis (na indústria, usinas termoelétricas, automóveis, etc.) é uma característica do atual modelo de sociedade, não se espera que as emissões de gases de efeito estufa diminuam significativamente nos próximos anos. Essa realidade nos leva a cenários futuros com elevadas concentrações de $\mathrm{CO}_{2}$ na atmosfera terrestre, que, segundo projeções descritas por MOSS et al. (2010), podem ser maiores que $1370 \mathrm{ppm}$ em 2100.

$\mathrm{O} \mathrm{CO}_{2}$ como substrato para a fotossíntese

A concentração de $\mathrm{CO}_{2}$ na atmosfera interfere diretamente em um importante processo fisiológico nos vegetais, a fotossíntese, processo em que as plantas transformam a energia luminosa em energia química, sintetizando compostos carbonados, que serão utilizados em diversos processos do metabolismo vegetal, além de ser fonte de energia para as demais formas de vida (TAIZ \& ZEIGER, 2013). Este importante metabolismo, responsável pela produção da biomassa vegetal, é abastecido pelo $\mathrm{CO}_{2}$ atmosférico, que entra na folha através dos estômatos, difundindo-se pelo parênquima até os cloroplastos, onde o processo fotossintético ocorre. Bioquimicamente, a fotossíntese consiste em uma série de reações químicas, em que inicialmente a luz é utilizada na quebra da molécula da água, gerando energia para o processo, que será concluído pela incorporação do carbono do $\mathrm{CO}_{2}$ em compostos orgânicos (TAIZ \& ZEIGER, 2013).

Plantas com metabolismo $\mathrm{C}_{3}$ são mais beneficiadas pelo aumento da concentração de $\mathrm{CO}_{2}$ atmosférico do que plantas com metabolismo $\mathrm{C}_{4}$ (TUBIELLO et al., 2000; SIQUEIRA et al., 2001; STRECK, 2005). Plantas com metabolismo $\mathrm{C}_{4}$, devido a modificações morfofisiológicas no aparato fotossintético, utilizam com eficiência o $\mathrm{CO}_{2}$ presente no ar atmosférico nas concentrações atuais. Resultados experimentais que mostram aumento na biomassa seca e rendimento comercial de algumas culturas em resposta ao dobro da concentração do $\mathrm{CO}_{2}$ são apresentados por STRECK (2005). O aumento varia de acordo com a cultura, sendo que o incremento médio é de $23 \%, 32 \%, 42 \%, 54 \%$ e $52 \%$ para frutas, cereais $\mathrm{C}_{3}$, folhosas, legumes e raízes, respectivamente.

O aumento da taxa fotossintética em função da maior concentração de $\mathrm{CO}_{2}$ na atmosfera é um efeito direto da atividade fisiológica das plantas em resposta ao ambiente. Entretanto, o incremento da fotossíntese não é constante ao longo do período de exposição e pode não ser permanente, ou seja, a intensidade da resposta das plantas é variável em função da espécie e da concentração de $\mathrm{CO}_{2}$. Além disso, a resposta pode ser reduzida após um período de exposição, em função de uma série de ajustes bioquímicos e/ ou metabólicos dos processos fisiológicos, em decorrência dessa exposição, processo denominado de aclimatação (CALIMAN, 2008). 
Aclimatação no curto prazo

O metabolismo vegetal, quando exposto a elevadas concentrações de $\mathrm{CO}_{2}$, passa por diversas alterações, que objetivam a autorregulação dos processos bioquímicos e fisiológicos, tendendo ao retorno ao estado inicial de equilíbrio. Essa autorregulação pode acontecer logo após o início da exposição, processo denominado de aclimatação a curto prazo, que ocorre na escala de tempo de minutos ou horas após o início da exposição ao $\mathrm{CO}_{2}$ elevado (CALIMAN, 2008). Diversos processos do metabolismo vegetal são afetados em um curto prazo após o aumento da concentração de $\mathrm{CO}_{2}$ atmosférico, como pode ser visualizado na figura 1 , e que serão descritos com mais detalhes no decorrer do texto.

\section{Limitação do processo fotossintético}

Quando há maior concentração de $\mathrm{CO}_{2}$, inicialmente, a taxa fotossintética aumenta, pois haverá mais $\mathrm{CO}_{2}$ nos sítios de troca da enzima Ribulose 1,5-bisfosfato carboxilase oxigenase (Rubisco), responsável pela carboxilação primária no Ciclo de Calvin-Benson, aumentando a produção de fotoassimilados. A maior concentração de $\mathrm{CO}_{2}$ na atmosfera faz com que a concentração deste gás no interior da folha também aumente (SOUZA et al., 2008), elevando a eficiência fotossintética por diminuir a fotorrespiração. A fotorrespiração, segundo TAIZ \& ZEIGER (2013), é o processo bioquímico em que a enzima Rubisco, responsável pela carboxilação na fotossíntese, catalisa a reação de oxigenação ao invés da carboxilação, por ter afinidade tanto pelo $\mathrm{CO}_{2}$ quanto pelo $\mathrm{O}_{2}$ em seu sítio ativo, o que caracteriza perda de eficiência no processo fotossintético. Como o $\mathrm{O}_{2}$ e o $\mathrm{CO}_{2}$ competem pelo mesmo sítio ativo, aumentando a concentração do $\mathrm{CO}$, no interior da folha, a reação de carboxilação será favorecida, aumentando a taxa fotossintética em ambiente com maior concentração de $\mathrm{CO}_{2}$ (SOUZA et al., 2008).

Devido à fotossíntese ser um processo bioquímico que depende da presença e atuação de diversas enzimas e moléculas, o aumento da taxa fotossintética não é contínuo ao longo do tempo (TAIZ \& ZEIGER, 2013). À medida que a fotossíntese aumenta, as enzimas (como a Rubisco) vão sendo consumidas no processo, e o metabolismo de regeneração dessas enzimas, além do suprimento de energia na forma de ATP, não é suficiente para atender à necessidade demandada pelos órgãos fotossintéticos (YELLE et al., 1989a; CHEN et al., 2005). Esta deficiência metabólica inicial é considerada uma das

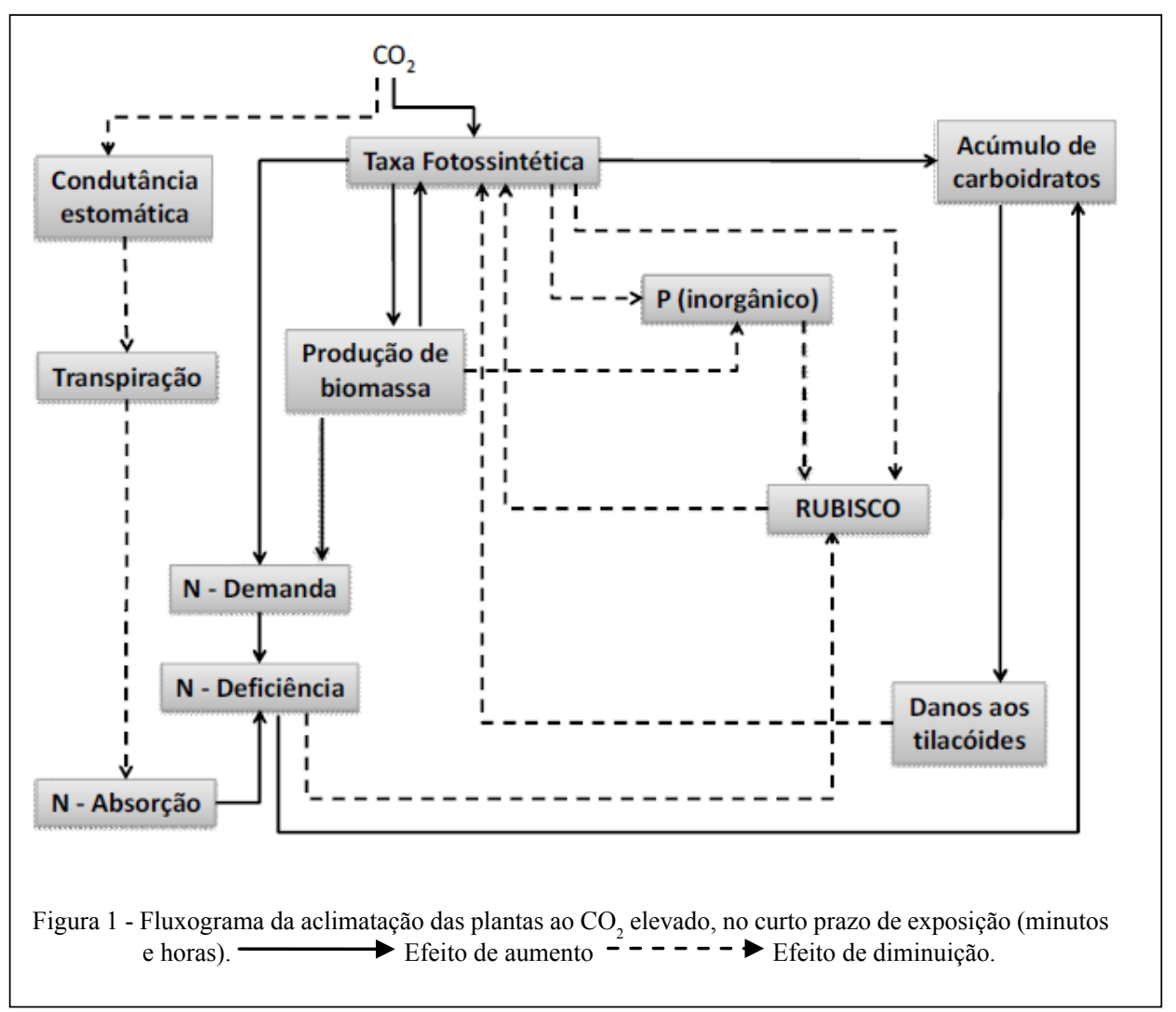

Ciência Rural, v.45, n.9, set, 2015. 
formas primárias de autorregulação do metabolismo, que ocorre por uma limitação na quantidade de enzima disponível para catálise do processo fotossintético (Figura 1). Portanto, num primeiro momento, o aumento da concentração de $\mathrm{CO}_{2}$ atmosférico aumenta a taxa fotossintética, que imediatamente fica limitada em função do maior consumo de Rubisco e energia, que não são supridas na mesma velocidade.

Acúmulo de carboidratos não estruturais

Mesmo com algumas limitações metabólicas, inicialmente, o aumento da taxa fotossintética em ambientes com elevada concentração de $\mathrm{CO}_{2}$ favorece a produção de biomassa vegetal (KRISHNAN et al., 2007). No final do processo de fotossíntese, são sintetizadas cadeias carbonadas, ou carboidratos, que serão posteriormente utilizados em diversas rotas metabólicas do vegetal, na síntese de outros compostos orgânicos, tanto estruturais (que constituirão a estrutura do vegetal), quanto compostos do metabolismo vegetal. Quando a produção de carboidratos é elevada, além da capacidade de síntese destas rotas metabólicas, nem todos os esqueletos carbonados produzidos são utilizados, acumulandose como carboidratos não estruturais, principalmente na forma de amido (DELUCIA et al., 1985) e sacarose. Maiores quantidades desses carboidratos não estruturais nas folhas das plantas que cresceram em ambiente com elevada concentração de $\mathrm{CO}_{2}$, comparado com as plantas que cresceram em $\mathrm{CO}_{2}$ ambiente, têm sido relatadas: aumento de amido e sacarose em 132 e 43\%, respectivamente, em Arabidopsis thaliana (BAE \& SICHER, 2004); $49 \%$ a mais amido acumulado em Senna reticulata (ARENQUE et al., 2014). O amido é sintetizado pelos vegetais quando há excesso de carboidratos disponíveis, sendo, portanto, uma forma de reserva (TAIZ \& ZEIGER, 2013). A síntese e o acúmulo do amido ocorrem no interior dos cloroplastos, organelas responsáveis também pela fotossíntese nos vegetais. Quando o acúmulo de amido é muito grande, poderá haver danos mecânicos nos tilacóides do cloroplasto, em função do crescimento excessivo dos grãos de amido, prejudicando o processo de fotossíntese e, portanto, reduzindo a taxa fotossintética (DELUCIA et al., 1985).

\section{Suprimento da demanda de nitrogênio}

Uma das principais rotas metabólicas para os carboidratos produzidos no processo fotossintético é a síntese de aminoácidos (TAIZ \& ZEIGER, 2013), precursores das proteínas. Neste processo, um grupo carboxila $(\mathrm{COOH})$ e um grupo amina $\left(\mathrm{NH}_{2}\right)$ são adicionados às cadeias carbonadas dos carboidratos, consumindo, entre outros compostos e enzimas, o nitrogênio $(\mathrm{N})$. A quantidade de nitrogênio presente no interior das folhas para este metabolismo é, portanto, outro fator limitante para a manutenção das altas taxas fotossintéticas em elevadas concentrações de $\mathrm{CO}_{2}$ atmosférico em curto prazo (KIM et al., 2011). $\mathrm{O}$ aumento da taxa fotossintética, juntamente com a maior produção de carboidratos, fará com que a demanda de $\mathrm{N}$ seja bastante elevada e este maior consumo de $\mathrm{N}$, consequentemente, ocasionará uma potencial deficiência de $\mathrm{N}$ nas folhas (Figura 1). Esse processo leva a outra forma de autorregulação, visto que, com a deficiência de $\mathrm{N}$, haverá acúmulo de carboidratos que não serão utilizados na síntese de aminoácidos (TRICKER et al., 2004). Além disso, o nitrogênio também é um dos principais componentes da molécula de clorofila, do ATP (fonte de energia para muitos processos metabólicos), e é componente essencial na ativação da Rubisco (TAIZ \& ZEIGER, 2013). Em função disso, a deficiência de $\mathrm{N}$ tem grande influência na taxa fotossintética, resultando em mais uma forma de autorregulação do metabolismo vegetal em elevadas concentrações de $\mathrm{CO}_{2}$ na atmosfera, segundo BAE \& SICHER (2004), se o suprimento de $\mathrm{N}$ é suficiente, a aclimatação à fotossíntese é mínima.

\section{Condutância estomática}

A maior concentração de $\mathrm{CO}_{2}$ atmosférico causa redução na condutância estomática (SHIMONO et al., 2010). A menor abertura estomática reduz as perdas de água por transpiração através dos estômatos, mas não compromete a concentração de $\mathrm{CO}_{2}$ no interior da folha. A hipótese de que a redução da condutância estomática seria um dos principais mecanismos de aclimatação ao $\mathrm{CO}_{2}$ elevado foi rejeitada quando se comprovou que a concentração interna de $\mathrm{CO}_{2}$ não foi alterada pela concentração externa (YELLE et al., 1989), ou seja, o aumento na diferença de concentração de $\mathrm{CO}_{2}$ entre a atmosfera e o interior da folha compensa o aumento da resistência pelo fechamento parcial dos estômatos, mantendo assim a concentração interna de $\mathrm{CO}_{2}$. Por outro lado, a baixa condutância estomática, observada em altas concentrações de $\mathrm{CO}_{2}$ atmosférico, leva a uma menor transpiração e, neste processo, com menos água sendo conduzida através do xilema, menos água é absorvida pelas raízes, consequentemente, menos nitrogênio é carregado pelo processo de absorção, pois a taxa de absorção de N ocorre em função da taxa de absorção de água (MALAVOLTA, 1980), podendo agravar o estado de deficiência de N. Considerando essa menor condutância estomática e a consequente redução 
da transpiração (SOUZA et al., 2008) e absorção de nutrientes, pode-se supor que as exigências de adubação (principalmente nitrogenada) sejam maiores em ambientes com elevada concentração de $\mathrm{CO}_{2}$ para se manter os atuais índices de produtividade. Além disso, a maior taxa fotossintética faz com que a demanda por nutrientes também aumente.

\section{Aclimatação em longo prazo}

Após este momento inicial, no qual os primeiros mecanismos de aclimatação se desenvolvem no metabolismo, a planta inicia um segundo processo na escala de tempo de dias e semanas, denominado de aclimatação em longo prazo. A aclimatação em longo prazo caracterizase pela necessidade de um período maior de exposição ao $\mathrm{CO}_{2}$ elevado para que as alterações no metabolismo comecem a se desenvolver (CALIMAN, 2008).

Apesar de algumas rotas metabólicas importantes serem prejudicadas no curto prazo (como a fotossíntese e a síntese de aminoácidos), a aclimatação não impede que a produção de biomassa nas plantas que crescem em elevada concentração de $\mathrm{CO}_{2}$ seja significativamente maior do que naquelas que crescem em $\mathrm{CO}_{2}$ ambiente. Segundo YANG et al. (2006), plantas de arroz irrigado (Oryza sativa), cultivadas em $\mathrm{CO}_{2}$ ambiente, produziram menor quantidade de biomassa total do que aquelas cultivadas em ambiente enriquecido com 200ppm de $\mathrm{CO}_{2}$. A razão da biomassa em $\mathrm{CO}_{2}$ elevado/ $\mathrm{CO}_{2}$ ambiente em porcentagem (\%), ou seja, a \% de mudança de biomassa produzida com incremento de $\mathrm{CO}_{2}$, variou ao longo do ciclo da cultura, com valores de 40,30, 22, 26 e 16\% para os estágios de perfilhamento, iniciação da panícula, florescimento, enchimento de grãos e maturação fisiológica, respectivamente, na média de três anos de experimentos FACE (Free-air $\mathrm{CO}_{2}$ enrichment) (YANG et al., 2006). Percebe-se, ao longo do ciclo da cultura, uma tendência de decréscimo da vantagem na produção de biomassa do ambiente enriquecido de $\mathrm{CO}_{2}$ sobre o ambiente natural, mostrando que o incremento inicial da produção de fotoassimilados não se mantém até o final do ciclo da cultura, o que indica aclimatação no longo prazo.

\section{Distribuição de biomassa}

Além de ser reduzido ao longo do ciclo da cultura, o incremento que ocorre na produção de biomassa em ambiente enriquecido com $\mathrm{CO}_{2}$ não é igualmente distribuído entre os diferentes compartimentos da planta, resultando, na maioria dos casos, num favorecimento da parte vegetativa em detrimento dos órgãos reprodutivos (ZISKA \& BOUNCE, 2000; YANG et al., 2006). Esse fato, porém, não significa que o rendimento de grãos das plantas que passaram por um processo de aclimatação ao $\mathrm{CO}_{2}$ elevado será menor, comparado ao ambiente natural, apenas indica que os grãos serão proporcionalmente menos favorecidos que os caules, por exemplo, resultando em um menor índice de colheita. Para a cultura da soja (Glycine max), os aumentos na biomassa total ao final do ciclo de desenvolvimento podem ser de 57 a $154 \%$ (dependendo da cultivar) com as plantas crescendo em CO elevado (ambiente $+300 \mathrm{ppm}$ ), comparados a apenas 25 a $78 \%$ de aumento no rendimento de grãos (ZISKA\& BOUNCE, 2000), indicando que o aumento na biomassa não foi correspondente ao aumento no rendimento de grãos. No tomateiro (CALIMAN et al., 2009), a produção de massa seca total foi maior em ambiente com enriquecimento de $\mathrm{CO}_{2}$, sendo o aumento de biomassa observado principalmente nos caules, sem efeito sobre a produção dos frutos. A aclimatação em longo prazo, portanto, pode estar relacionada à alocação dos fotoassimilados nos órgãos reprodutivos, e isso exige uma capacidade de aumento do tamanho, ou do número destes compartimentos na planta (CALIMAN, 2008).

\section{Órgãos de armazenamento}

A capacidade de aumento dos compartimentos para alocação de fotoassimilados, ou seja, o desenvolvimento de novos drenos na planta de soja em ambiente com elevada concentração de $\mathrm{CO}_{2}$ (550ppm) foi estudado por AINSWORTH et al. (2004). O experimento testou duas cultivares de soja diferentes quanto ao hábito de crescimento (determinado e indeterminado), comparando-as com suas respectivas isolinhas com o hábito de crescimento alterado pela modificação de um único gene. $\mathrm{O}$ hábito de crescimento determinado refere-se àquelas cultivares em que o período de floração é curto e seu início coincide com o final do desenvolvimento vegetativo. Cultivares indeterminadas são aquelas que continuam o desenvolvimento vegetativo quando inicia o florescimento, permitindo um período de floração mais prolongado. Quando uma cultivar de hábito determinado é modificada para apresentar crescimento indeterminado, espera-se que o potencial produtivo se eleve, já que o período de floração será mais prolongado, podendo aumentar o número de vagens produzidas, o contrário também verdadeiro (uma cultivar indeterminada quando modificada para hábito determinado deve ter seu potencial produtivo reduzido). Os resultados de AINSWORTH et al. (2004) mostram que a cultivar indeterminada teve maior capacidade fotossintética e menor acúmulo 
de carboidratos não estruturais, principalmente na forma de amido, do que sua isolinha determinada, indicando um desequilíbrio na relação fonte-dreno (redução do dreno) ocasionado pelo menor potencial produtivo do hábito determinado. A fotossíntese e o acúmulo de carboidratos não estruturais da cultivar de hábito determinado não apresentaram diferença significativa de sua isolinha indeterminada em elevada concentração de $\mathrm{CO}_{2}$ (AINSWORTH et al., 2004). Os autores associam este fato ao já elevado potencial produtivo da cultivar determinada utilizada e ressaltam que o efeito da aclimatação é dependente da base genética de cada material.

CHEN \& SETTER (2012) avaliaram o acúmulo de biomassa em plantas de batata (Solanum tuberosum) submetidas a 700ppm de $\mathrm{CO}_{2}$, concluindo que a partição de biomassa favorece o crescimento dos colmos até o início da tuberização, quando os tubérculos, principais órgãos de armazenamento da batata, passam a ser beneficiados pela maior taxa fotossintética. $\mathrm{O}$ excedente de fotoassimilados produzidos pelo aumento do $\mathrm{CO}_{2}$ disponível para a fotossíntese é acumulado na forma de amido nos tubérculos da planta, fazendo com que o tamanho destes órgãos seja significativamente maior em condições de $\mathrm{CO}_{2}$ elevado.

Plantas de arroz irrigado submetidas a elevadas concentrações de $\mathrm{CO}_{2}$ foram avaliadas quanto à distribuição da biomassa produzida entre os diferentes compartimentos da planta: folhas colmos e panículas, em diferentes estágios de desenvolvimento ao longo do ciclo (YANG et al., 2006). A figura 2 foi construída a partir dos dados médios extraídos da tabela 3 do trabalho de YANG et al. (2006) e mostra a porcentagem de mudança ocorrida na distribuição da biomassa na planta em função da maior concentração de $\mathrm{CO}_{2}$ em um experimento FACE, conduzido na China durante 3 estações de cultivo. Os resultados de YANG et al. (2006) indicam que, comparativamente ao ambiente natural, em maiores concentrações de $\mathrm{CO}_{2}$ na atmosfera, uma fração menor da biomassa produzida foi alocada nas folhas, com um aumento na fração alocada nos colmos (Figura 2). Proporcionalmente, a planta de arroz produziu maior quantidade de colmos do que folhas, sugerindo que, em ambiente enriquecido com $\mathrm{CO}_{2}$, o aumento da taxa fotossintética resultou em maior acúmulo de biomassa nos órgãos de reserva. O maior incremento de biomassa nos órgãos de reserva em relação às folhas é um indicativo de que ocorre um desequilíbrio na relação fonte-dreno e, neste caso, a alta taxa fotossintética resulta na produção de um número elevado de cadeias carbonadas, as quais o vegetal não consegue metabolizar totalmente e acabam sendo destinadas aos órgãos de reserva.

Os grãos, assim como os colmos, também são órgãos de reserva, porém, os resultados de YANG et al. (2006) indicam uma tendência diferente dos colmos para o acúmulo de biomassa nos grãos de arroz. Em um primeiro momento, no aparecimento da panícula (estágio 3), a fração de biomassa destinada aos grãos é proporcionalmente menor no ambiente enriquecido com $\mathrm{CO}_{2}$ (Figura 2), pois neste momento os colmos ainda são drenos mais fortes que os grãos, recebendo a maior fração dos fotoassimilados produzidos (YANG et al., 2006). Durante o enchimento de grãos (estágio 4), a panícula do arroz passa a ter prioridade na partição de fotoassimilados e este órgão é favorecido pelo aumento da concentração de $\mathrm{CO}_{2}$ na atmosfera. $\mathrm{O}$ excedente de produtos da fotossíntese em ambiente enriquecido com $\mathrm{CO}_{2}$ é, portanto, alocado nos órgãos de armazenamento de reservas do arroz (colmos e grãos), aumentando o potencial produtivo da cultura.

A planta de arroz possui uma característica morfológica que limita o potencial produtivo e resulta na redução da vantagem da partição de biomassa para a panícula em ambiente enriquecido com $\mathrm{CO}_{2}$ no estágio de maturação fisiológica, como pode ser observado na figura 2. A panícula do arroz é composta por espiguetas (que darão origem aos grãos), cada espigueta é formada por invólucros externos chamados de lema e pálea, que serão a casca do grão. No processo de enchimento dos grãos de arroz, a lema e a pálea servem como limitadores do crescimento do grão, por serem estruturas rígidas, fazem com

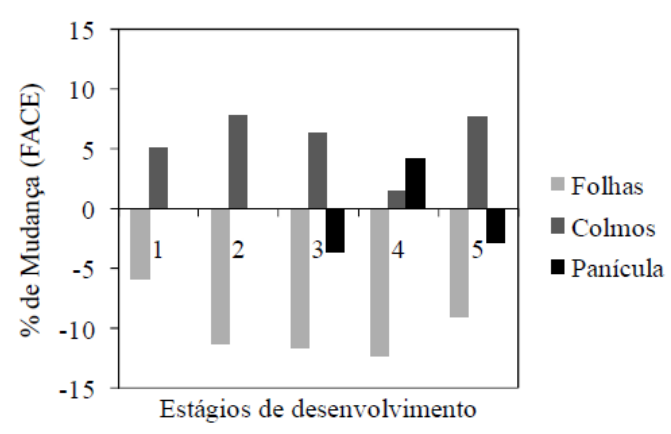

Figura 2 - Porcentagem de mudança na distribuição da biomassa para os principais compartimentos da planta de arroz em ambiente enriquecido com $\mathrm{CO}_{2}$ (FACE), em relação ao $\mathrm{CO}_{2}$ ambiente, com avaliações em diferentes estágios de desenvolvimento. 1 (perfilhamento), 2 (iniciação floral), 3 (aparecimento da panícula), 4 (enchimento de grãos) e 5 (maturidade fisiológica). Adaptado de Yang et al. (2006). 
que o tamanho e peso dos grãos de um determinado material de arroz apresentem variabilidade muito pequena (CAMARGO et al., 2008; LARROSA et al., 2009). Em ambiente enriquecido com $\mathrm{CO}_{2}$, a maior produção de fotoassimilados favoreceu o rendimento final de grãos de arroz (YANG et al., 2006), porém, o potencial produtivo poderia ser ainda maior se não ocorresse a aclimatação. Nesta espécie vegetal, um dos mecanismos de aclimatação no longo prazo é a limitação do dreno, pela barreira física que a lema e a pálea representam para o crescimento dos grãos, assim, os fotoassimilados remanescentes são direcionados para os colmos, aumentando novamente a porcentagem de mudança deste compartimento no ambiente enriquecido com $\mathrm{CO}_{2}$ (Figura 2).

\section{CONCLUSÃO}

A aclimatação ocorre nas plantas devido a adaptações morfofisiológicas, podendo ser observada no curto e no longo prazo de exposição ao $\mathrm{CO}_{2}$. No decorrer de algumas horas, ou minutos, observa-se a aclimatação no curto prazo, quando enzimas e outras substâncias importantes para a fotossíntese começam a ficar escassas pelo metabolismo acelerado, além disso, o amido excedente da elevada taxa fotossintética, acumulado no interior de cloroplastos, pode prejudicar a fotossíntese. Num período de dias ou semanas, observa-se um decréscimo da vantagem produtiva, do ambiente com elevado $\mathrm{CO}_{2}$, ao longo do ciclo da cultura e uma distribuição da biomassa que favorece as partes vegetativas. A aclimatação no longo prazo está relacionada com a capacidade de o vegetal aumentar seus compartimentos de armazenamento, tanto em número, quanto em tamanho.

\section{AGRADECIMENTOS}

À Coordenação de Aperfeiçoamento de Pessoal de Nível Superior (CAPES) e ao Conselho Nacional de Desenvolvimento Científico e Tecnológico (CNPq), pela concessão de bolsas.

\section{REFERÊNCIAS}

AINSWORTH, E.A. et al. Testing the "source-sink" hypothesis of down-regulation of photosynthesis in elevated $\left[\mathrm{CO}_{2}\right]$ in the field with single gene substitutions in Glycine max. Agricultural and Forest Meteorology, v.122, p.85-94, 2004. Disponível em: $<$ http://www.bnl.gov/pubweb/alistairrogers/linkable_files/pdf/ AgForMet-122-85.pdf $>$. Acesso em: 8 mar. 2015. doi: 10.1016/j. agrformet.2003.09.002.

ARENQUE, B.C. et al. Responses of Senna reticulata, a legume tree from the Amazonian flood plains, to elevated atmospheric $\mathrm{CO}_{2}$ concentration and water logging. Trees, v.28, p.1021-1034, 2014. doi: 10.1007/s00468-014-1015-0.

BAE, H.; SICHER, R. Changes of soluble protein expression and leaf metabolite levels in Arabidopsis thaliana grown in elevated atmospheric carbon dioxide. Field Crops Research, v.90, n.6173, 2004. Disponível em: <http://www.ars.usda.gov/SP2UserFiles/ ad_hoc/12755100FullTextPublicationspdf/Publications/sicher/ arabidopsis2004.pdf $>$. Acesso em: 8 mar. 2015. doi: 10.1016/j. fcr.2004.07.005.

CALIMAN, F.R.B. Enriquecimento com $\mathrm{CO}_{2}$ por meio de compostagem para a cultura do tomateiro em ambiente protegido. 2008. 79f. Tese (Doutorado em Fitotecnia) - Programa de Pós-graduação em Fitotecnia, Universidade Federal de Viçosa, Viçosa, MG.

CALIMAN, F.R.B. et al. Enriquecimento intermitente de $\mathrm{CO}_{2}$ e análise do acúmulo de massa seca e da partição de fotoassimilados em tomateiro. Acta Agronómica, v.58, n.3, p.133-139, 2009. Disponível em: <http://www.scielo.org.co/pdf/acag/v58n3/ v58n3a03.pdf $>$. Acesso em: 8 mar. 2015.

CAMARGO, E.R. et al. Influência da aplicação de nitrogênio e fungicida no estádio de emborrachamento sobre o desempenho agronômico do arroz irrigado. Bragantia, v.67, n.1, p.153-159, 2008. Disponível em: <http://www.scielo.br/pdf/brag/v67n1/ a19v67n1.pdf>. Acesso em: 19 nov. 2012. doi: 10.1590/S000687052008000100019 .

CHEN, G.Y. et al. Photosynthetic acclimation in rice leaves to free-air $\mathrm{CO}_{2}$ enrichment related to both ribulose-1,5-bisphosphate carboxylation limitation and ribulose-1,5-bisphosphate regeneration limitation. Plant Cell Physiology, v.46, n.7, p.1036-1045, 2005. Disponível em: <http://pcp.oxfordjournals. org/content $/ 46 / 7 / 1036$. full.pdf + html? sid $=15$ e 8 b52b-b76c4195-b41f-0b62218f155a>. Acesso em: 15 jun. 2013. doi:10.1093/pcp/pci113.

CHEN, C.T.; SETTER, T.L. Response of potato dry matter assimilation and partitioning to elevated $\mathrm{CO}_{2}$ at various stages os tuber initiation and growth. Environmental and Experimental Botany, n.80, p.27-34, 2012. Disponível em: <http://ac.els-cdn. com/S009884721200041X/1-s2.0-S009884721200041X-main. pdf?_tid=329781 c8-c680-11e4-94eb-00000aacb360\&acdnat $=142$ $59216430557 \mathrm{bf} 87 \mathrm{~d} 2 \mathrm{~b} 0 \mathrm{fdb} 4 \mathrm{a} 71944770 \mathrm{f0d} 3 \mathrm{~d} 3 \mathrm{~b}>$. Acesso em: 8 mar. 2015. doi: 10.1016/j.envexpbot.2012.02.003.

DELUCIA, E.H. et al. Photosynthetic inhibition after longterm exposure to elevated levels of atmospheric carbon dioxide. Photosynthesis Research, v.7, n.2, p.175-184, 1985. doi: 10.1007/ BF00037008.

INTERGOVERNMENTAL PANEL ON CLIMATE CHANGE (IPCC). Climate change 2007: the physical science basis. Contribution of working group I to the fourth assessment report of the intergovernmental panel on climate change. Cambridge: Cambridge University, 2007. 996p. Disponível em: <https://www. ipcc-wg1.unibe.ch/publications/wg1-ar4/wg1-ar4.html>. Acesso em: 27 maio 2013.

INTERGOVERNMENTAL PANEL ON CLIMATE CHANGE (IPCC). Summary for Policymakers. In: Climate Change 2013: The Physical Science Basis. Contribution of Working Group I to the Fifth Assessment Report of the Intergovernmental Panel on Climate Change [Stocker, T.F. et al. (eds.)]. Cambridge: 
Cambridge University, 2013. 33p. Disponível em: $<$ http://www. climatechange2013.org/images/report/WG1AR5_SPM_FINAL. pdf $>$. Acesso em: 20 jan. 2014.

KIM, H.Y. et al. Dry matter and nitrogen accumulation and partitioning in rice (Oryza sativa L.) exposed to experimental warning with elevated $\mathrm{CO}_{2}$ Plant Soil, v.342. p.59-71, 2011. doi: 10.1007/s11104-010-0665-y.

KRISHNAN, P. et al. Impact of elevated $\mathrm{CO}_{2}$ and temperature on rice yield and methods of adaptation as evaluated by crop simulation studies. Agriculture Ecosystems \& Environment, v.122,p.233-242, 2007. Disponível em: <http://www.sciencedirect. com/science/article/pii/S016788090700045X\#>. Acesso em: 8 mar. 2015. doi: 10.1016/j.agee.2007.01.019.

LARROSA, R.M. et al. Doses e épocas de aplicação de nitrogênio na suscetibilidade do arroz à temperatura baixa na fase reprodutiva. Ciência Rural, v.39, n.4, p.992-997, 2009. Disponível em: <http:// www.scielo.br/pdf/cr/v39n4/a185cr835.pdf > . Acesso em: 17 abr. 2013. doi: 10.1590/S0103-84782009005000079.

MALAVOLTA, E. Elementos de nutrição mineral de plantas. São Paulo: Agronômica Ceres, 1980. 251p.

MANN, M.E. et al. Northern hemisphere temperatures during the past millennium: inferences, uncertainties, and limitations. Geophysical Research Letters, v.26, n.6, p.759762, 1999. Disponível em: <http://onlinelibrary.wiley.com/ doi/10.1029/1999GL900070/epdf>. Acesso em: 8 mar. 2015. doi: 10.1029/1999GL900070.

MOSS, R.H. et al. The next generation of scenarios for climate change research and assessment. Nature, v.463, p.747-756, 2010. doi:10.1038/nature08823.

NATIONAL OCEANIC \& ATMOSPHERIC ADMINISTRATION (NOAA). Earth System Research Laboratory - Global Monitoring Division. Ed Dlugokencky \& Pieter Tans. Trends in Atmospheric Carbon Dioxide. Recent Global $\mathbf{C O}_{2}$. Janeiro/2014. Obtido via base de dados NOAA. 2014. Online. Disponível em: <http://www.esrl. noaa.gov/gmd/ccgg/trends/global.html>. Acesso em: 20 mar. 2014.

SHIMONO, H. et al. Effect of panicle removal on photosynthetic acclimation under elevated $\mathrm{CO}_{2}$ in rice. Photosynthetica, v.48, n. 4 , p. 530-536, 2010.

SIQUEIRA, O.J.W. et al. Efeitos potenciais das mudanças climáticas na agricultura brasileira e estratégias adaptativas para algumas culturas. In: LIMA, M.A. et al. Mudanças climáticas globais e a agropecuária brasileira. Jaguariúna, SP: EMBRAPA Meio Ambiente, 2001. p.33-63. Disponível em: <http://ivraria.sct.embrapa. br/liv_resumos/pdf/00071250.pdf $>$. Acesso em: 29 ago. 2013.
SOUZA, A.P. et al. Elevated $\mathrm{CO}_{2}$ increases photosynthesis, biomass and productivity, and modifies gene expression in sugarcane. Plant, Cell and Environment, v.31, p.1116-1127, 2008. doi: $10.1111 / \mathrm{j} .1365-3040.2008 .01822 . x$.

STRECK, N.A. Climate change and agroecosystems: the effect of elevated atmospheric $\mathrm{CO}_{2}$ and temperature on crop growth, development, and yield. Ciência Rural, v.35, n.3, p.730-740, 2005. Disponível em: <http://www.scielo.br/pdf/cr/v35n3/a41v35n3.pdf> . Acesso em: 15 ago. 2012. doi: 10.1590/S0103-84782005000300041.

TAIZ, L.; ZEIGER, E. Fisiologia vegetal. 5.ed. Porto Alegre:Artemed, 2013. 954p.

TRICKER, P.J. et al. Long-term acclimation of leaf production, development, longevity and quality following $3 \mathrm{yr}$ exposure to free-air $\mathrm{CO}_{2}$ enrichment during canopy closure in Populus. New Phytologist, v.162, n.2, p.413-426, 2004. Disponível em: <http:// onlinelibrary.wiley.com/doi/10.1111/j.1469-8137.2004.01057.x/ pdf $>$. Acesso em: 23 jul. 2013. doi: 10.1111/j.14698137.2004.01057.x.

TUBIELLO, F.N. et al. Effects of climate change and elevated $\mathrm{CO}_{2}$ on cropping systems: model predictions at two Italian locations. European Journal of Agronomy, v.13, p.179-189, 2000. Disponível em: <http://ac.els-cdn.com/S1161030100000733/1s2.0-S1161030100000733-main.pdf?_tid=202cc93ec68b-11 e4-8e86-00000aab0f02\&acdnat $=1425926337$ a9f675dafc3ba33c07d45234b42fc5dc >. Acesso em: 8 mar. 2015. doi: 10.1016/S1161-0301(00)00073-3.

von STORCH, H. et al. Reconstructing past climate from noisy data. Science, v.306, p.679-682, 2004.

YANG, L. et al. Seasonal changes in the effects of free-air $\mathrm{CO}_{2}$ enrichment (FACE) on dry matter production and distribution of rice (Oryza sativa L.). Field Crops Research, v.98, p. 12-19, 2006. Disponível em: <http://ac.els-cdn.com/S0378429005002613/1s2.0-S0378429005002613-main.pdf? tid=92b9ad3c-c68b-11e4826c-00000aacb35e\&acdnat $=1425926529 \_75 \mathrm{e} 027 \mathrm{c} 646 \mathrm{eb} 6 \mathrm{~b} 9 \mathrm{e}$ 7332e1491ad273c7>. Acesso em: 8 mar. 2015. doi: 10.1016/j. fcr.2005.11.003.

YELLE, S. et al. Acclimation of to two tomato species to high atmospheric $\mathrm{CO}_{2}$ : I. sugar and starch concentrations. Plant Physiology, v.90, p.1465-1472, 1989. Disponível em: <http:// www.plantphysiol.org/content/90/4/1465.full.pdf $+\mathrm{html}>$. Acesso em: 27 jan. 2013. doi: 10.1104/pp.90.4.1465.

ZISKA, L.H.; BUNCE, J.A. Sensitivity of field-grown soybean to future atmospheric $\mathrm{CO}_{2}$ : selection for improved productivity in the 21st century. Australian Journal of Plant Physiology, v.27, n.10, p.979-984, 2000. 